\title{
Diesel Engine Emissions and Performance Characteristics under Cape Chestnut Biofuel
}

\author{
Jedidah W. Maina ${ }^{1 *}$, Ayub N. Gitau ${ }^{1}$, James A. Nyang'aya ${ }^{2}$ \\ ${ }^{1}$ Department of Environmental and Biosystems Engineering, University of Nairobi, Nairobi, Kenya; ${ }^{2}$ Department of Mechanical and \\ Manufacturing Engineering, University of Nairobi, Nairobi, Kenya. \\ Email: ${ }^{*}$ jedidahwm@gmail.com
}

Received October $9^{\text {th }}, 2013$; revised November $11^{\text {th }}, 2013$; accepted November $19^{\text {th }}, 2013$

Copyright (C) 2013 Jedidah W. Maina et al. This is an open access article distributed under the Creative Commons Attribution License, which permits unrestricted use, distribution, and reproduction in any medium, provided the original work is properly cited.

\begin{abstract}
Cape Chestnut oil was processed to biodiesel through transesterification. Cape Chestnut kennels are reported to have oil content of $60 \%$ - 63\% [1]. Properties of biodiesel were determined and compared with those of diesel and engine tests done at a constant speed of 1500 RPM on the biodiesel blends to evaluate their performance and emissions characteristics. Performance evaluation was in terms of Brake Specific Fuel Consumption (BSFC), Brake Horse Power (BHP) and Brake Thermal Efficiency (ETE). The engine was initially run on diesel to establish the reference characteristics before running on biodiesel blends. The biodiesel was blended with diesel volumetrically to 80\% (B80), 50\% (B50), 20\% (B20) and 5\% (B5) the percentage being the volume of biodiesel in the blended fuel. Diesel fuel had the lowest BSFC followed by B5 whose BSFC was 7.3\% higher than that of diesel. BTE for B100 was lower than that of diesel by $20.3 \%$ while that of $\mathrm{B} 5$ was $7.6 \%$ lower. Concentration of $\mathrm{SO}_{2}$ in $\mathrm{B} 100$ was $92.7 \%$ lower than that of diesel fuel while that of B20 was $24.7 \%$ lower. $\mathrm{NO}$ and $\mathrm{NO}_{2}$ concentrations for $\mathrm{B} 100$ were around $15 \%$ higher than that of diesel. Particulate matter of less than $10 \mu \mathrm{m}$ diameter (PM10) for diesel was found to be $72 \%$ of the total collected from all the test fuels as compared to that of biodiesel blends at $28 \%$. The study concluded that Cape Chestnut biodiesel blends containing up to $20 \%$ biodiesel can be used in an unmodified diesel engine since their performance and emission characteristics were very similar to that of diesel but with reduced toxic gas emissions therefore friendly to the environment.
\end{abstract}

Keywords: Biodiesel; Transesterification; Performance; Emissions; Brake Specific Fuel Consumption; Brake Horse Power; Engine Thermal Efficiency

\section{Introduction}

Biofuels are broadly defined as liquids, solids or gaseous fuels that are predominantly or exclusively produced from biomass. The main types of biofuels include ethanol, biodiesel and biogas derived from crops residues or wastes. All of these can be used as substitutes or supplements for the traditional fossil fuels used for transportation, domestic and industrial uses [2]. It has been the focus of considerable amount of recent research because it is renewable and reduces the emissions of some pollutants [3]. Before recommending any alternative biofuel to be used in existing technologies on a large scale, the environmental compatibility factor has to be considered as compared to conventional fuel [4].

Increased industrialization and urbanization of the

${ }^{*}$ Corresponding author. world have led to a steep rise in demand of petroleum based fuels. Fossils fuels which constitute $80 \%$ of primary energy consumed in the world are the primary contributors to Greenhouse Gas Emissions (GHG). Biofuels are considered environmentally friendly in that they are renewable, biodegradable, natural lubricants and generate acceptable quality of exhaust gases. Recently because of the increase in crude oil prices, limited resources of fossil oil and environmental concerns, there has been a renewed focus in vegetable oils and animal fats to make biodiesel [4].

Kenya spent more than Kshs 230 million to import fuel and other lubricants in 2010 [5]. The annual average price of oil increased from US $\$ 79.16$ per barrel in 2010 to US \$110.6 per barrel in 2011 and the demand of petroleum products grew by 1.9 per cent from 3867.1 thousand tones in 2010 to 3941.6 thousand tones in 2011 [6]. Household 
cooking is another important application where biofuels can replace charcoal and firewood. Indoor air pollution is reduced as clean burning fuels and vegetable oils replace traditional biomass which contributes to respiratory illness [7].

Since 1990, research into the manufacture and use of biofuels has grown. It has been reported that carbonyl compound emissions for diesel powered vehicles have exceeded those from conventional gasoline vehicles [8]. The depletion of easily accessible supplies of oil and the high cost of extracting oils from deep seas, remote areas and politically unstable regions have contributed to renewed interest in biofuels as an alternative and renewable supply of transport fuels and to policies in many countries that encourage production and mandate consumption of biofuels. Concerns over global climate change have also contributed to the renewed interest in biofuels such as the desire for increased energy security and to support the rural sector. The rapid increase in global demand for biofuels over the next decade or more will provide opportunities for Africa exporters because neither EU nor US is expected to meet its consumption mandates completely from domestic production [7].

In Kenya today, the commercial energy sector is dominated by petroleum and electricity as the prime movers of modern sector of the economy while wood fuel provides energy needs of the traditional sector including rural communities and the urban poor. At the national level wood fuel and other biomass account for about $68 \%$ of the total primary energy consumption followed by petroleum at $22 \%$, electricity at $9 \%$ and others less than $1 \%$ [9]. The Government has enacted a policy paper [9] and Legislation [10] that favors the development of bioethanol and biodiesel. Therefore there is need to develop biodiesel locally which can be produced most efficiently and effectively considering the land use, environment, economic and social issues.

\section{Materials and Methods}

The engine tests were carried out on a Nissan TD27 diesel engine model.

\subsection{Test Engine}

The engine used was a turbo charged water cooled Nissan TD27 4 Cylinder with rated maximum power of 62 $\mathrm{Kw} / 4300 \mathrm{rpm}$. The engine was set to run at a constant speed of $1500 \mathrm{rpm}$. The test engine was coupled to a hydraulic G-type Froude dynamometer. The loads were applied by regulating the amount of water going into the dynamometer, with load increments in steps of $0.225 \mathrm{Kg}$.

The engine was connected to a pipette to measure fuel consumption as shown in Figure 1. The $150 \mathrm{ml}$ pipette was to determine the fuel consumption. The fuel to the

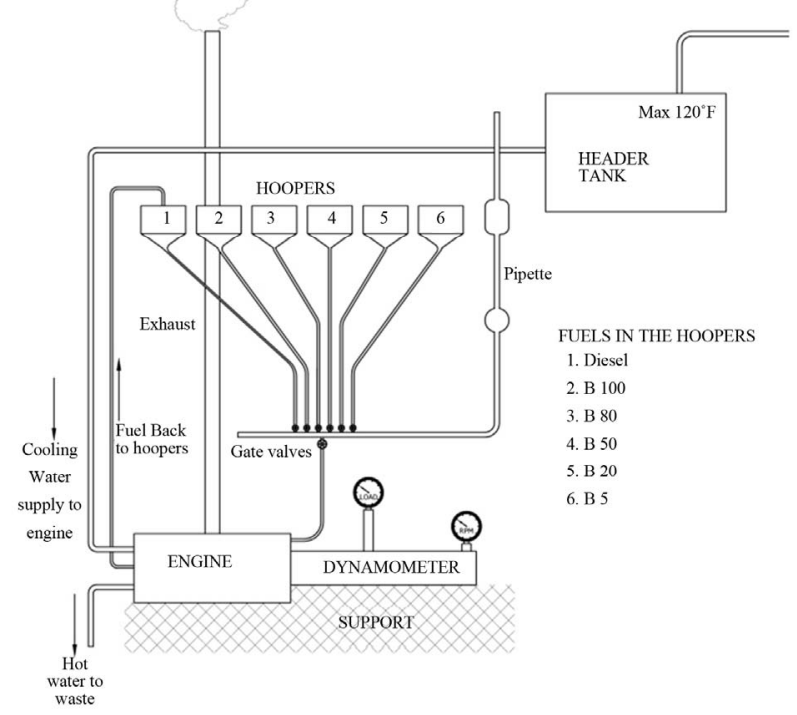

Figure 1. Test diesel engine assembly.

engine was supplied from special hoppers/containers arranged as shown in Figure 1. Each of the containers was filled with a different fuel blend. With diesel, B100, $\mathrm{B} 80, \mathrm{~B} 50, \mathrm{~B} 20$ and B5 in the respective containers labeled 1, 2, 3, 4, 5 and 6 . Individual gate valves on the fuel lines facilitated the changing to any of the fuel blends for engine testing.

\subsection{Fuel System}

The fuel system consisted of fuel hoppers, delivery lines, fuel filters, and injector pumps injector nozzles and over flow lines. From the fuel hoppers, fuel flows by gravity through the delivery lines to the filters to the injector pumps.

\subsection{Cooling System}

The engine set up was water-cooled, with water flow assisted by the engine's water pump. The external circuit was via a header tank, fitted with a thermometer. The water temperature in the header tank was maintained at $120^{\circ} \mathrm{F}\left(49^{\circ} \mathrm{C}\right)$ by supplying cold water from the mains and allowing the same amount of hot water to pass to waste from the system. Thermometers were fitted to measure the inlet and outlet water temperatures at the engine.

\subsection{Portable Toxic Gas Monitor}

These are instruments used to detect and analyze toxic vapours from the exhaust gases of the test engine. The instruments were portable, light and easy to use. Each digital measurements of a particular exhaust gas emission in low concentrations were viewed in real time from the monitors. The emission gases which were detected and 
monitored were; $\mathrm{SO}_{2}, \mathrm{NO}$ and $\mathrm{NO}_{2}$. In order to detect and measure the particulate matter (PM10) filters were attached to the engine exhaust pipe. The readings from the monitors were analyzed in real time of the engine.

\subsection{Transesterification}

The oil was transesterified using methanol as alcohol and Potassium Hydroxide $(\mathrm{KOH})$ as the catalyst. Every liter of Cape Chestnut oil required $200 \mathrm{ml}$ of methanol and the amount of Potassium Hydroxide was $1 \%$ by weight of the Methanol used. The catalyst was kept dry in an airtight container during the storage since water promotes saponification. The required amount of catalyst was measured and dissolved in the alcohol before pouring into the corresponding volume of the Cape Chestnut oil. The mixture was stirred and covered to avoid evaporation of the alcohol into the atmosphere and left to settle for $24 \mathrm{hrs}$ after which there was a clear distinction of biodiesel at the top and glycerin which settled at the bottom. The alcohol (methanol) reacted with the fatty acids in the Cape Chestnut oil in the presence of the catalyst (Potassium Hydroxide) to form mono alkyl (biodiesel) and glycerin.

\subsection{Separation and Washing of the Biodiesel}

After transesterification and overnight settling, results showed methyl esters and glycerin distinctively separate. Glycerin is denser and therefore settled at the bottom of the container. The mixture needed to be separated and this was done by sucking out the biodiesel from the top of the container and leaving glycerin at the bottom to be disposed of.

\subsection{Biodiesel Drying}

After gently washing three times with warm water, the biodiesel was left overnight in the open for the evaporation to take place and by the following day, all the water had evaporated and biodiesel was ready for blending and testing.

The process of biodiesel production from transesterification, separation, washing and drying took three days to complete where upon blending was done by measuring the necessary volumes of biodiesel. The volumes of biodiesel were 5, 20, 50 and 80 per cent while the balance of the volume to make 100 per cent was diesel to make B5, $\mathrm{B} 20, \mathrm{~B} 50$ and B80 blends respectively.

\subsection{Biodiesel Fuel Properties}

\subsubsection{Calorific Value}

This was done with the help of a bomb calorimeter.

$$
\mathrm{HCV}=\frac{\mathrm{CT} \times \mathrm{TWE} \text { in } \mathrm{kj}}{\text { Mass of Fuel }}
$$

where HCV = Higher Calorific Value; TWE = Total water equivalence in calories; $\mathrm{CT}=$ Corrected temperature.

A graph was drawn to determine the corrected temperature rise and then the Equation (1) employed.

Total water equivalent $=$ volume of water in calorimeter + water equivalent of bomb.

\subsubsection{Specific Gravity}

The specific gravity of fuel is necessary to determine the power input of the fuel and hence determine the thermal efficiency and BSFC. Thermal efficiency, brake horse power and BSFC were the parameters used to determine the performance of the fuels in the study. The value of 908 $\mathrm{Kg} / \mathrm{m}^{3}$ [1] for the density of Cape Chestnut Methyl Ester was used.

The specific gravity of the blends was calculated using Equation (2) [11].

$$
\mathrm{SG}_{\text {blend }}=\sum \mathrm{SG}_{i} \times X_{i}
$$

where $\mathrm{SG}_{\text {blend }}$ is the specific gravity of blend and $\mathrm{SG}_{i}$ is the specific gravity of component fuels and $X_{i}$ is the volume fraction of the mass $i$.

\subsection{Fuel Consumption Measurement}

The various fuels were used in turns to run the engine. The time taken by test engine to consume $150 \mathrm{ml}$ of each fuel as indicated by the pipette was recorded. In order to start the process the pipette was filled with fuel well above the top marking by opening the main supply valve. The engine was operated on the main supply while isolating the fuel from the pipette. The main supply valve was then closed and the engine operated on the fuel from the pipette to determine the consumption. Subsequently, the load was increased by intervals of $0.225 \mathrm{Kg}$ until the engine started to run with difficulty at which point the load was considered to be the maximum for that particular fuel at that speed.

\subsection{Measurement of Exhaust Gases}

The fuel consumption was recorded concurrently with sampling of the emissions by the monitors attached to the engine's exhaust pipe. The emissions monitors were recording the detected toxic gases $\mathrm{NO}, \mathrm{SO}_{2}$ and $\mathrm{NO}_{2}$ at intervals of every ten seconds in parts per million (ppm).

To evaluate the particulate matter emitted by fuels, a filter was attached to the engine exhaust pipe which enabled it to pick any PM10 emitted as the exhaust gases exited. Two filters were used, for the diesel and the other for B100, B80, B50, B20 and B5. The reason why only one filter was used for all the CCME and its blends is because the PM10 in them was almost negligible for each to be considered independently.

\subsection{Evaluation of Exhaust Emission Gases and Particulate Matter}

The evaluations were done for the exhaust emissions from 
each fuel running the diesel engine and their quantities in ppm compared to that of diesel. The emission gases under consideration were $\mathrm{NO}, \mathrm{SO}_{2}$ and $\mathrm{NO}_{2}$. Particulate matter was also analyzed for neat CCME and its blends and a comparison was also done with No 2 diesel. To illustrate the comparison, graphs were drawn to show the trends of each emission gas with time as the engine load was increased which was analyzed as real time. Comparisons were also done on the fuels to determine the trend on increasing the percentage of biodiesel in blend with conventional diesel.

\subsection{Determination of Brake Power}

The loading of the engine was done through the dynamometer which in this study was hydraulic. Brake power which is the engine power output was calculated from the load to the engine through dynamometer, dynamometer shaft speed which in our case was constant at $1500 \mathrm{rpm}$. As specified earlier the dynamometer used was Froude Type-G hydraulic dynamometer. The manufacturer recommended the Equation (3) below to determine the engine brake power.

$$
\text { Brake Power }=\frac{W \times N \times 0.7457}{200}
$$

where $W=$ Weight in pounds;

$N=$ Dynamometer shaft speed in RPM;

0.7457 and 200 are constants.

\subsection{Determination of Brake Specific Fuel Consumption (BSFC)}

This is calculated from the engine brake power, time $(\mathrm{t})$ taken to consume the fuel, density and volume of the fuel because it is the mass flow rate of fuel consumed per unit power output. It is expressed in $\mathrm{Kg} / \mathrm{Kw}$ as shown in Equation (4).

$$
\text { BSFC }=\frac{\text { Density } \times \text { Volume } \times 3600}{t \times \text { Brake Power }}(\mathrm{Kg} / \mathrm{Kw} \cdot \mathrm{h})
$$

where: $t=$ time taken in seconds to consume a particular volume of fuel.

\subsection{Determination of Thermal Efficiency}

This is engine brake power output as a percentage of the brake power input of the fuel. Therefore to determine the thermal efficiency, power input had to be determined first and Equation (5) employed.

Powe Input $=\frac{\text { Density } \times \text { Volume } \times \text { heating value }}{t}(\mathrm{Kw})(5)$

where: $t$ is the time taken to consume a particular volume of fuel.

After evaluating the power input it was then possible to determine the thermal efficiency as illustrated in Equation (6).

$$
\text { Thermal Efficiency }=\frac{\text { Brake Power }}{\text { Powe Input }}(\%)
$$

\section{Results and Discussion}

\subsection{Engine Performance}

The engine performance tests carried out were to determine the BSFC, BHP and thermal efficiencies of B5, B20, B50, B80 and B100 Cape Chestnut biodiesel blends. The results were compared to those of diesel under the same conditions. Graphs were drawn of BSFC and thermal efficiency each against BHP for all the biodiesel blends and diesel.

\subsubsection{Effect of Blending on Brake Specific Fuel Consumption (BSFC)}

Table 1 shows the results of the variation of BSFC with brake power for the diesel, Cape Chestnut Methyl Ester (CCME) and their various blends. The brake specific fuel consumption (BSFC) in all the fuels tested decreased as brake power (BP) increased up to and until BHP of $11 \mathrm{Kw}$ as shown in Figure 2.

\subsubsection{Effect of Blending on Thermal Efficiency}

Table 2 shows the results of thermal efficiencies while Figure 3 shows the trend of thermal efficiency as plotted against brake horse power for all the test fuels. At the break power of $11 \mathrm{Kw}$ the thermal efficiency difference between diesel and B100 was found to be $8.99 \%$ which was a decrease of $31 \%$.

\subsection{Analysis of Exhaust Gases from the Test Engine}

The tests were done to detect and determine the concentration of and types of gases in the exhaust emissions during the running of the engine on Cape Chestnut biodiesel blends and therefore compared with their concentration during use of diesel fuel. The exhaust emission gases

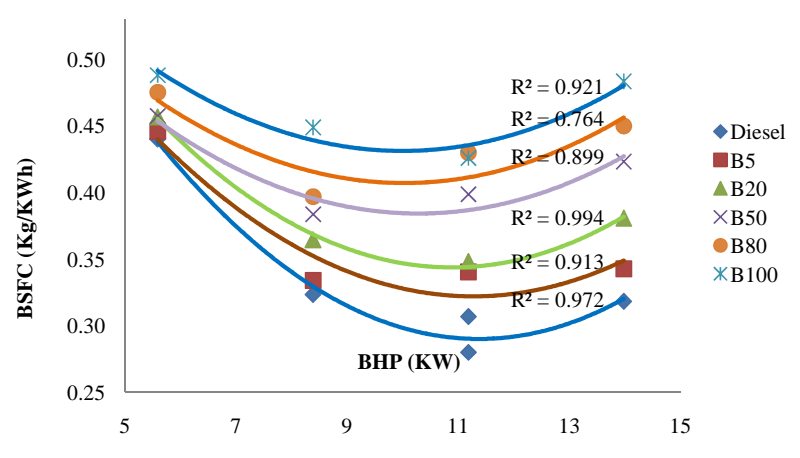

Figure 2. BFSC Vs BHP. 
Table 1. Brake specific fuel consumption for test fuels.

\begin{tabular}{cccccccc}
\hline BHP (Kw) & \multicolumn{7}{c}{ Brake Specific Fuel Consumption (BSFC), Kg/Kw·h } \\
\hline & Diesel & B5 & B20 & B50 & B80 & B100 \\
5.593 & 0.444 & 0.446 & 0.457 & 0.457 & 0.475 & 0.488 \\
8.389 & 0.323 & 0.334 & 0.364 & 0.384 & 0.397 & 0.449 \\
11.186 & 0.28 & 0.340 & 0.348 & 0.399 & 0.430 & 0.426 \\
$\underline{13.982}$ & $\underline{0.318}$ & $\underline{0.343}$ & $\underline{0.381}$ & $\underline{0.405}$ & $\underline{0.490}$ & $\underline{0.483}$ \\
\hline
\end{tabular}

Table 2. Thermal efficiency of the test fuels.

\begin{tabular}{cccccccc}
\hline BHP (Kw) & \multicolumn{7}{c}{ Brake Thermal Efficiency, \% } \\
\hline & Diesel & B5 & B20 & B50 & B80 & B100 \\
\hline 5.593 & 18.258 & 18.143 & 18.069 & 18.798 & 18.093 & 18.948 \\
8.389 & 24.852 & 24.222 & 22.644 & 22.412 & 21.669 & 20.603 \\
11.186 & 28.706 & 23.771 & 23.693 & 21.573 & 20.001 & 21.715 \\
13.982 & 25.256 & 23.607 & 21.684 & 20.319 & 18.500 & 19.13 \\
\hline
\end{tabular}

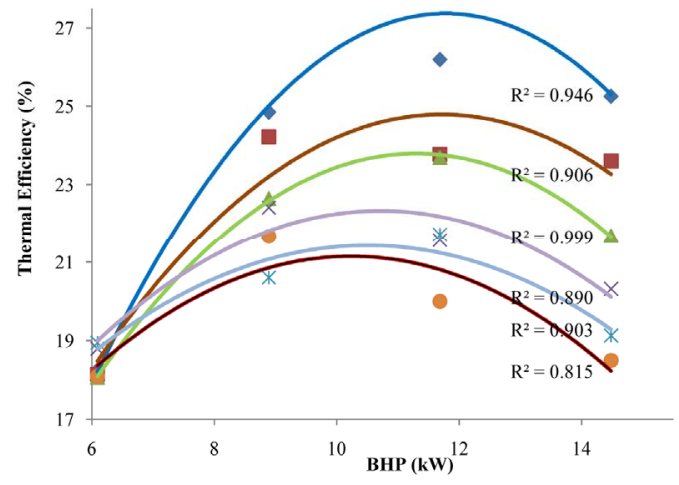

Figure 3. Thermal efficiency Vs BHP.

in the study were the $\mathrm{SO}_{2}, \mathrm{NO}_{2}$, and $\mathrm{NO}$.

\subsubsection{Analysis of $\mathrm{SO}_{2}$ Emissions from the Test Fuels}

The exhaust gases from the test fuels were analysed and the results of $\mathrm{SO}_{2}$ concentration are as shown in Table 3 . As brake power increased, the $\mathrm{SO}_{2}$ emissions in the fuels increased reaching a peak at about $11 \mathrm{Kw}$ as shown on Figure 4. The $\mathrm{SO}_{2}$ at $11 \mathrm{Kw}$ for $\mathrm{B} 100$ was $2.161 \mathrm{ppm}$ and 19.917 ppm for No. 2 diesel an reduction of 17.756 ppm which is $89 \%$ reduction in emissions.

\subsubsection{Analysis of NO Emissions from the Test Fuels}

As shown in the graphs in Figure 5, as brake horse power was increased, NO emissions concentrations showed a linear increament. B100 was found to have the highest NO emissions of $2.042 \mathrm{ppm}$ as compared to diesel with 1.874 ppm at BHP of $13.98 \mathrm{Kw}$.

\subsection{3. $\mathrm{NO}_{2}$ Emissions from the Test Fuels}

$\mathrm{NO}_{2}$ emissions for all the test fuels were found to decrease

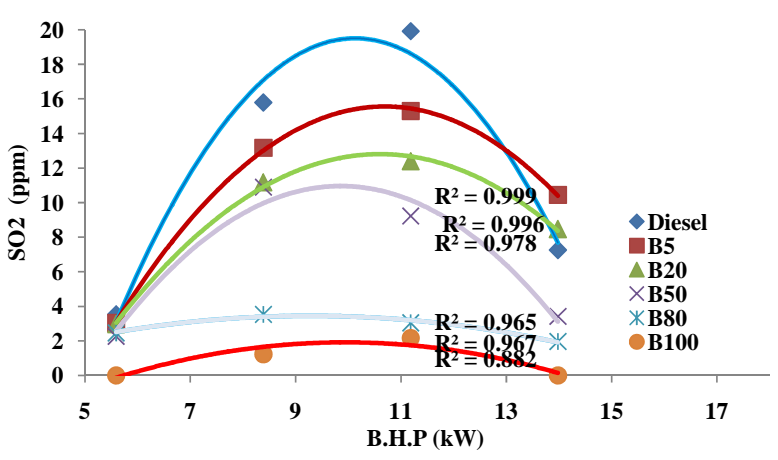

Figure 4. The variation of $\mathrm{SO}_{2}$ with $\mathrm{BHP}$ for test fuels.

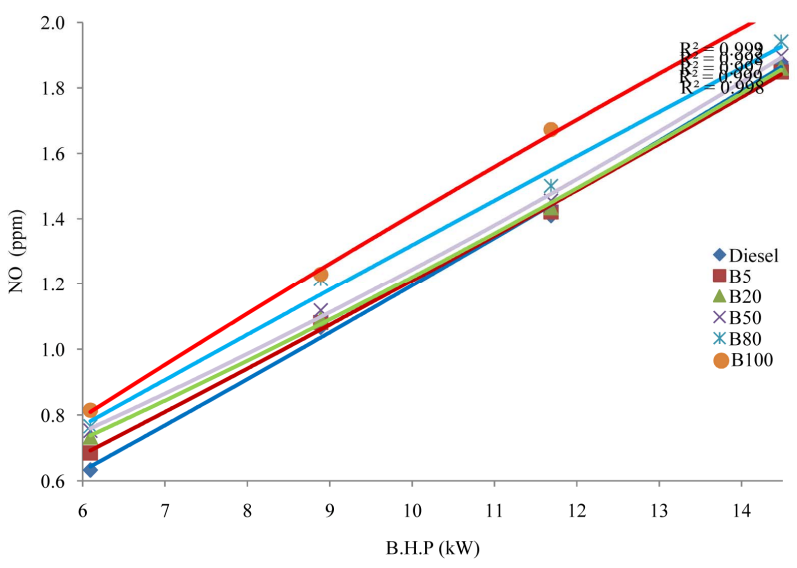

Figure 5. The variation of NO with BHP for test fuels.

with the increase of BHP up to around BHP of $11 \mathrm{Kw}$ and were found to rise as BHP increased. The $\mathrm{NO}_{2}$ emissions detected in diesel at BP of about $11 \mathrm{Kw}$ was $0.442 \mathrm{ppm}$ while B100 was 0.529 ppm a deviation of 0.087 ppm from that of diesel and an increase of $19.7 \%$. 
Table 3. $\mathrm{SO}_{2}$ emissions for test fuels.

\begin{tabular}{cccccccc}
\hline BHP (Kw) & \multicolumn{3}{c}{ SO $_{\mathbf{2}}(\mathbf{p p m})$} \\
\hline & Diesel & B5 & B20 & B50 & B80 & B100 \\
5.593 & 3.524 & 3.033 & 2.963 & 2.267 & 2.467 & 0.000 \\
8.389 & 15.789 & 13.167 & 11.173 & 10.892 & 3.533 & 1.233 \\
11.186 & 19.917 & 15.300 & 12.400 & 9.229 & 3.050 & 2.161 \\
13.982 & 7.258 & 10.447 & 8.458 & 3.418 & 1.967 & 0.000 \\
\hline
\end{tabular}

\subsubsection{Concentration of Particulate Matter (PM) in the Test Fuels}

Particulate matter detected while carrying out the tests were of two types, fine and course particles. diesel fuel had $78 \%$ of the total percentage of fine particles detected while biodiesel blends combined had $22 \%$.

\section{Conclusions}

The study analysis concluded that:

- The use of biodiesel leads to reduced engine power as observed in the high BSFC as the volumetric percentage of biodiesel increased in the blends. The use of biodiesel in small amounts in the blends with diesel resulted in insignificant power loss.

- The main reason for power loss is attributed to reduced heating value of the biodiesel as compared to diesel fuel because of its high density therefore more volume of biodiesel is needed to produce equivalent power output as compared to diesel.

Where modification to an engine is done the injection feature of biodiesel is influential to engine power considering biodiesel has a higher density and viscosity.

\section{Acknowledgements}

My sincere thanks to the Departments of Environmental and Biosystems Engineering and Mechanical and Manufacturing Engineering of the University of Nairobi for providing support in the course of the research of this work.

\section{REFERENCES}

[1] A. W. Wagutu, S. C. Chhabra, C. L. Thoruwa, T. F. Thoruwa and R. L. A. Mahunnah, "Indigenous Crops as a
Source for Production of Biodiesel in Kenya. Bull," Chemical Society of Ethiopia, Vol. 23, No. 3, 2009, pp. 359-370.

[2] E. Sulle and F. Nelson, "Biofuels Land Access and Rural Livelihoods in Tanzania,” IIED, London, 2009.

[3] A. Monyem and J. H. V. Gerpen, "The Effect of Biodiesel oxidation on Engine Performance and Emissions," Biomass and Bioenergy, Vol. 20, No. 2001, 1999, pp. 317-325.

[4] A. K. Agarwal, "Bio-Fuels (Alcohols and Biodiesel) Applications as Fuels forInternal Combustion Engines," Progress in Energy and Combustion Science, Vol. 33, No. 3, 2006, pp. 233-271.

http://dx.doi.org/10.1016/j.pecs.2006.08.003

[5] Kenya National Bureau of Statistics, "Leading Economic Indicators,” 2010.

[6] Kenya Bureau of Statistics, "Economic Survey Highlights,” 2012.

[7] D. Mitchel, "Bio-fuels in Africa: Opportunities, Prospects and Challenges,” The International Bank for Reconstruction and Development, The World Bank, 2011.

[8] Y. Liu, T. Lin, Y. Wang and W. Ho, "Carbonyl Compounds and Toxicity Assessments of Emissions from a Diesel Engine Running on Biodiesels," Journal of the Air and Waste Management Association, Vol. 59, No. 2, 2009, pp. 163-171. http://dx.doi.org/10.3155/1047-3289.59.2.163

[9] Government of Kenya, Ministry of Energy, "Sessional Paper No. 4 on Energy,” Government Press, 2004.

[10] Government of Kenya, Ministry of Energy, “The Energy Act No. 12 of 2006,” Government of Press, 2006.

[11] D. L. Clements, "Blending Rules for Formulating Biodiesel Fuel,” National Biodiesel Board, 1996. 